Gut, 1976, 17, 511-516

\title{
Intestinal perfusion studies in tropical sprue
}

\section{Amino acid and dipeptide absorption}

\author{
M. D. HELliER, A. N. RADHAKRISHNAN, V. GANAPATHY, V. I. MATHAN, \\ AND S. J. BAKER
}

From the Wellcome Research Unit, ${ }^{1}$ Christian Medical College Hospital, Vellore-632004, Tamil Nadu, India

SUMMARY Intestinal absorption of glycine $20 \mathrm{mmol} / 1$, glycyl-glycine $10 \mathrm{mmol} / \mathrm{l}$, glycine $10 \mathrm{mmol} / 1$ plus L-leucine $10 \mathrm{mmol} / 1$, and glycyl-L-leucine $10 \mathrm{mmol} / \mathrm{l}$ has been studied by intestinal perfusion in 11 patients with tropical sprue and 10 control subjects. The patients with sprue had a significant reduction in the rate of absorption of glycine from a $20 \mathrm{mmol} / 1$ solution, but there were no significant differences in the absorption of the other substances. The failure to demonstrate any difference in the absorption of these substances is probably related to their low concentration relative to the maximum absorptive capacity of the intestine. In both groups of subjects the kinetic advantage of glycyl-glycine absorption as compared with glycine absorption was maintained. When the dipeptides were perfused, free amino acids appeared in the perfusate presumably by 'back diffusion' from the mucosal cells. In the case of glycyl-L-leucine considerably more glycine and leucine were found in the perfusate in patients with sprue than in the control subjects. There was no correlation between peptide absorption and the concentration of total glycyl-glycine hydrolase and glycyl-L-leucine hydrolase, measured as combined brush border and cytosol enzymes. The concentrations of these enzymes were similar in both groups of subjects.

Tropical sprue has been defined as a syndrome of small intestinal malabsorption of unknown aetiology occurring among residents of, or visitors to, the tropics. It has further been suggested that for the diagnosis to be made there should be malabsorption of at least two test substances (Klipstein and Baker, 1970). Various test substances have been employed in the past, and the ability of patients with tropical sprue to absorb fat, carbohydrate, and some vitamins has been extensively studied. However, because suitable methods of testing are so few, very little data are available about amino acid or peptide absorption in this condition.

The aim of the present study was to investigate amino acid and peptide absorption in patients with chronic tropical sprue, using the quantitative technique of intestinal perfusion.

\section{Methods}

SUBJECTS STUDIED

Eleven subjects with tropical sprue and 10 control

'Wellcome Trust in Association with World Health Organization.

Received for publication 23 March 1976 subjects from the same socioeconomic group, and of comparable age and sex, were studied. In all cases the nature of the test was explained to the subjects and their informed consent for the investigations obtained.

All subjects were studied in a metabolic ward and were given a standard diet containing $50 \mathrm{~g}$ of fat per day. Before the perfusion studies they underwent a period of assessment including daily faecal fat estimation and repeated tests of xylose and vitamin $\mathrm{B}_{12}$ absorption. Faecal fat was estimated by the method of van de Kamer et al. (1959). Xylose absorption was tested by giving a $5 \mathrm{~g}$ dose of d-xylose and measuring the excretion in the urine in the subsequent five hours, by the method of Roe and Rice (1948). Vitamin $B_{12}$ absorption was measured using an oral dose of $1 \mu \mathrm{g}(0.5 \mu \mathrm{c}){ }^{57} \mathrm{CoB}_{12}$ and measuring the rise in serum radioactivity eight hours later-a rise of more than $0.2 \%$ of the test dose per litre of plasma being considered normal (Mathan et al., 1973). Jejunal biopsies were obtained in all subjects for enzyme studies and histological assessment using a Crosby capsule (Crosby and Kugler, 1957).

The control subjects were either symptomless or had minor vague complaints with no evidence of 511 
gastrointestinal disease. All had normal absorption of fat and vitamin $B_{12}$, but three had reduced excretion of xylose $(13,17$, and $22 \%$ in five hours). Their jejunal biopsies were similar to those of apparently healthy Indian subjects (Baker and Mathan, 1972).

The eleven subjects with tropical sprue had all been ill for more than six months. At the time of study all had diarrhoea with increased stool volume; all had steatorrhoea with the excretion of from 8 to $19 \mathrm{~g}$ fat per day; all had xylose malabsorption and excreted only 5 to $16 \%$ of the dose in five hours and six had vitamin $B_{12}$ malabsorption. Jejunal biopsies all showed changes compatible with the diagnosis of tropical sprue (Baker and Mathan, 1972).

\section{PERFUSION STUDIES}

Direct measurements of absorption were made using a double lumen perfusion technique incorporating a proximal occlusive balloon (Hellier et al., 1970). The tube was passed on the morning of the test after an overnight fast. Under radiological control the infusion port was placed just distal to the duodenojejunal flexure. The position of the tube was also checked from time to time during the study.

The following four solutions were used: (1) glycine $20 \mathrm{mmol} / \mathrm{l}$; (2) glycyl-glycine $10 \mathrm{mmol} / \mathrm{l}$; (3) glycine $10 \mathrm{mmol} / \mathrm{l}+\mathrm{L}$-leucine $10 \mathrm{mmol} / \mathrm{l}$, and (4) glycyl-Lleucine $10 \mathrm{mmol} / \mathrm{l}$. Amino acid and the equivalent dipeptide solutions were chosen in order to compare their relative rates of absorption. Solutions were made up with $0 \cdot 15 \mathrm{M}$ saline incorporating polyethylene glycol (PEG $4 \mathrm{mg} / \mathrm{ml}$ ) as a non-absorbable marker. The osmolality in each case was approximately $300 \mathrm{~m}$ Osm and the $\mathrm{pH}$ was adjusted to 7.0. Solutions were perfused in randomised order at $15 \mathrm{ml} / \mathrm{min}$ over a $30 \mathrm{~cm}$ segment. For each solution after a 30 minute equilibration period, three 10 minute samples were collected. Samples were collected on ice, and those for dipeptide analysis were acidified to $\mathrm{pH} 1$ to reduce any tendency for hydrolysis of dipeptide. Each sample was then centrifuged to remove any debris and frozen at $-20^{\circ} \mathrm{C}$ to await analysis. Polyethylene glycol was measured by the method of Hyden (1955). Amino acids were measured as copper complexes using a quantitative paper chromatographic method developed in this laboratory using $75 \%$ ethanol as the eluent (Das and Radhakrishnan, 1973). Dipeptides were measured as cadmium complexes, by a similar paper chromatographic method, using $80 \%$ methanol as the eluent and the spraying agent described by Atfield and Morris (1961) (1).

Glycyl-glycine hydrolase and glycyl-L-leucine hydrolase were estimated in mucosal biopsy fragments by the spectrophotometric assay method of Josefsson and Lindberg (1965) modified to achieve optimal conditions by using a $50 \mathrm{mmol} / \mathrm{l}$ concentration of the substrates.

\section{CALCULATIONS AND BACK-DIFFUSION}

Details of the formulae for calculating absorption have been described previously (Hellier et al., 1970). During dipeptide absorption free amino acids accumulate in the lumen. These arise to a variable extent from brush border hydrolysis and backdiffusion of amino acids from the cell after intact dipeptide uptake, depending on the dipeptide. For uniformity in calculating absorption, free amino acids are treated as though they resulted from hydrolysis of dipeptide before dipeptide uptake and an appropriate correction made to dipeptide absorption rates to allow for this. Treating the data in this way tends to underestimate dipeptide absorption.

\section{Results}

The results of individual tests are shown in Fig. 1. The mean absorption rates for $20 \mathrm{mmol} / 1$ glycine were significantly lower in the sprue group than in the controls, whereas with all the other solutions there were no significant differences in absorption rates. In the patients with sprue there was no correlation between these absorption rates, the results of xylose and fat absorption studies, or biopsy changes.

When absorption of glycine from a solution of the amino acid was compared with absorption from a solution of the dipeptide glycyl-glycine, absorption from the latter was greater in all except two individuals (Fig. 2). The mean kinetic advantage for glycine from the dipeptide solution was $30 \%$ in the control subjects and $34.5 \%$ in the patients with sprue. In both groups there was no kinetic advantage for either glycine or leucine as the dipeptide glycyl-L-leucine, when compared with an equimolar mixture of the free amino acids.

The appearance of amino acids in the aspirate during the perfusion of glycyl-glycine and glycyl-Lleucine is shown in Fig. 3. In the case of glycylglycine $10 \mathrm{mmol} / 1$ the appearance rates of glycine were similar in the two groups, though the mean rate was lower in the tropical sprue groups. However, in the case of glycyl-L-leucine the amounts of both glycine and leucine appearing in the perfusate were much greater in patients with tropical sprue, the difference being statistically significant $(\mathrm{P}<0.025$ and $<0.01$ respectively). In both groups the amount of leucine in the aspirate was very much less than that of glycine.

Dipeptidase levels for both dipeptides studied were measured in jejunal biopsies in eight of 10 


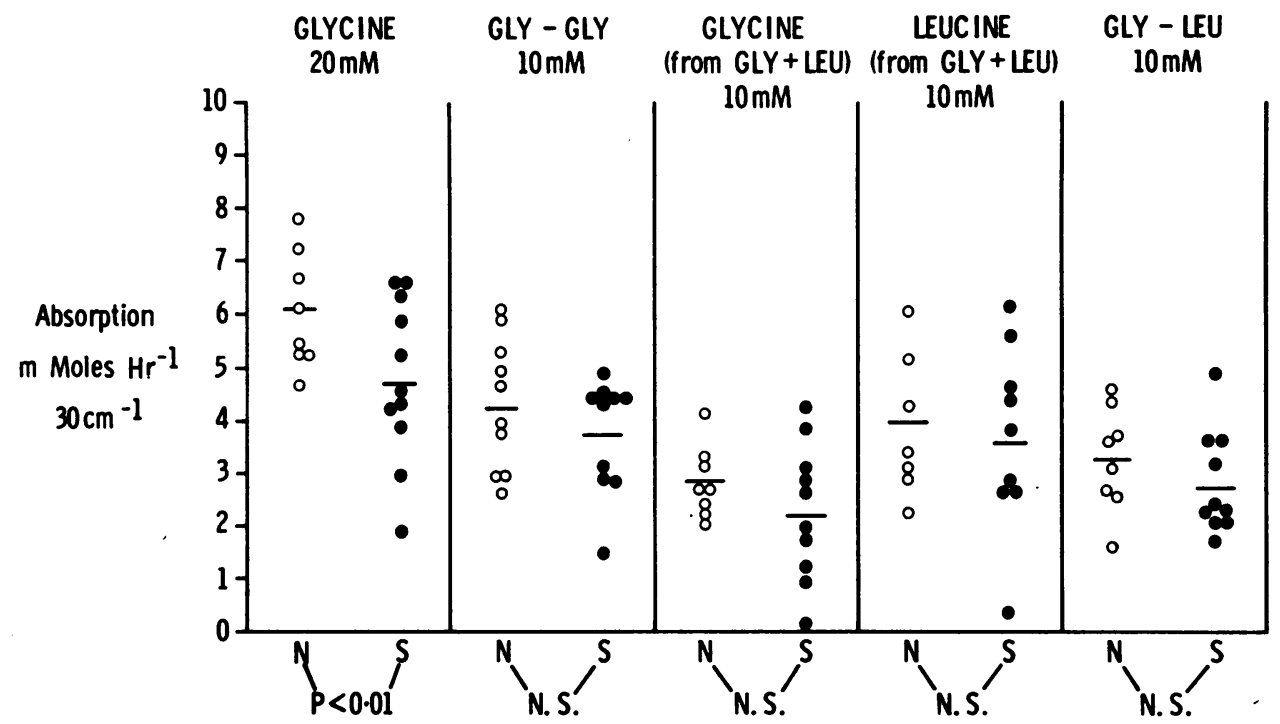

Fig. 1 Absorption of (1) glycine (20 mmol/l), (2) glycyl-glycine (10 mmol/l), (3) a solution containing glycine $(10 \mathrm{mmol} / \mathrm{l})$ and leucine $(10 \mathrm{mmol} / \mathrm{l})$ and $(4) \mathrm{glycyl}-\mathrm{L}-\mathrm{leucine}(10 \mathrm{mmol} / \mathrm{l})$. For each solution absorption is compared in normal Indians $(N)$ and patients with tropical sprue $(S)$. Absorption is expressed in mmol/l of amino acid or dipeptide $h^{-1} 30 \mathrm{~cm}^{-1}$ and $\mathrm{P}$ values for the differences between the groups are given at the bottom of the figure.

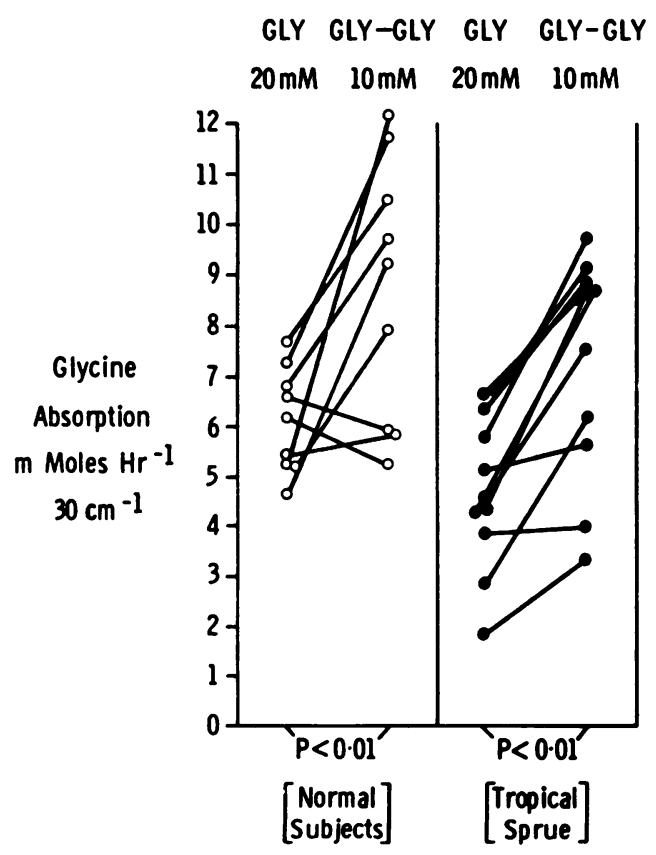

Fig. 2 Glycine absorption from a $20 \mathrm{mmol} / \mathrm{l}$ free glycine solution compared with its absorption from a $10 \mathrm{mmol} / \mathrm{l}$ glycyl-glycine solution in normal Indians and patients with tropical sprue. Absorption is expressed in mmol/l of glycine absorbed per hour per $30 \mathrm{~cm}$ segment. $P$ values for the differences in the groups are given below the figure. normal subjects and 10 of 11 patients with tropical sprue (Fig. 4). The mean enzyme levels for the two dipeptidases were almost identical in both groups.

\section{Discussion}

\section{GLYCINE MALABSORPTION}

Butterworth et al. (1958) tested glycine absorption in patients with tropical sprue by giving a $25 \mathrm{~g}$ oral load and studying plasma glycine concentrations. Their results suggested impairment of glycine absoption in the upper intestine. This is confirmed by the present study, using a more direct technique for measuring intestinal absorption.

\section{APPARENT SIMILARITY BETWEEN PATIENTS \\ WITH SPRUE AND CONTROLS}

When the patients with sprue were compared with the control subjects with respect to xylose, fat, and vitamin $B_{12}$ absorption, and intestinal biopsy findings, there was a clear-cut difference between the two groups. It was therefore surprising that with glycine $20 \mathrm{mmol} / \mathrm{l}$ there was considerable overlap between the two groups and with the other substances there were no detectable differences. The results of perfusion studies depend specifically on mucosal function, whereas fat, xylose, and $\mathbf{B}_{12}$ absorption tests are indirect indicators of absorption which may be influenced by multiple factors, apart from mucosal damage. It is therefore possible that there 


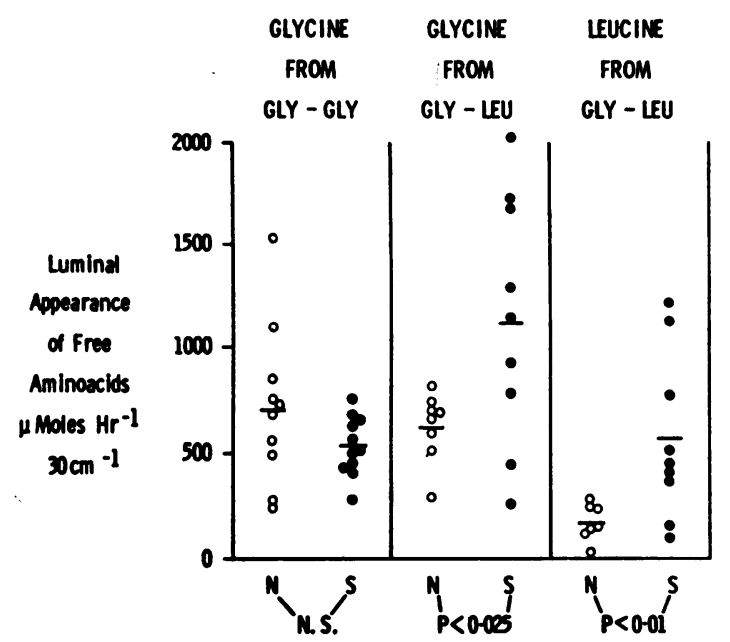

Fig. 3 The rate of appearance of free glycine and leucine within the lumen during perfusion of gly-gly and gly-leu in normal Indians and patients with tropical sprue. $P$ values for the differences between the groups are given below the figure. Appearance rate is expressed in $\mathrm{mmol} / \mathrm{l} \mathrm{h} \mathrm{h}^{-1} 30 \mathrm{~cm}^{-1}$.

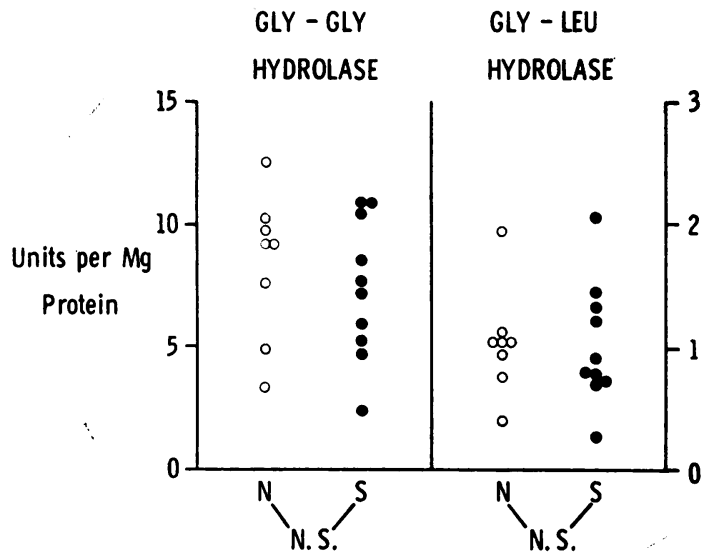

Fig. 4 Glycyl-glycine and glycyl-L-leucine hydrolase levels in jejunal biopsies from normal Indians and patients with tropical sprue undergoing perfusion. Enzyme activity is expressed in units per mg protein. P values for the differences between the groups are given below the figure.

is little difference in the impairment of mucosal cell function in the sprue patients when compared with the controls. The results of perfusion tests in these control subjects have already indicated impaired absorption when compared with normal Western subjects (Hellier et al., 1976) and it is possible that the more marked structural changes in sprue (Mathan et al., 1975) are not accompanied by significantly greater functional derangement. This implies that the fat, xylose, and vitamin $B_{12}$ malabsorption in the sprue patients is due to factors other than disordered mucosal cell function, which seems improbable.

Alternatively the 'loads' presented to the intestinal mucosa in these perfusion studies may be inadequate fully to stress the mucosal amino acid and peptide transport mechanisms. The fact that in the present study perfusion with a $10 \mathrm{mmol} / \mathrm{l}$ solution of glycine, albeit in the presence of leucine, did not show a significant difference between the two groups whereas a $20 \mathrm{mmol} / 1$ solution did, supports this hypothesis. A similar phenomenon occurs, for example, with xylose absorption. When a xylose test is carried out with a $1 \mathrm{~g}$ dose instead of a $5 \mathrm{~g}$ dose, the test fails to separate normal subjects from those with tropical sprue (Baker, personal observation), while a $25 \mathrm{~g}$ dose gives better separation between normal and abnormal subjects than a $5 \mathrm{~g}$ dose (Joske and Haagensen, 1964; Rinoldo and Gluckmann, 1964).

Silk et al. (1974) studied amino acid and peptide absorption in patients with coeliac disease. They perfused a $10 \mathrm{mmol} / 1$ solution of glycyl-L-alanine and an equimolar mixture of the amino acids. They found that the absorption of glycine and L-alanine, when presented as amino acids, was significantly reduced in their patients and controls. However, as in the present study, dipeptide absorption was not significantly reduced even in subjects with extensive mucosal damage. On the other hand, Adibi et al. (1974) studied five patients with probable coeliac sprue and found a marked reduction in the rate of glycyl-glycine and glycyl-L-leucine absorption as compared with control subjects. These investigators, however, used a $50 \mathrm{mmol} / 1$ concentration of the dipeptide providing a greater 'stress' to the damaged mucosa.

\section{KINETIC ADVANTAGE OF GLYCYL-GLYCINE} The relative sparing of glycyl-glycine, as compared with glycine absorption in the present study, means that the relative kinetic advantage of glycyl-glycine absorption in subjects with sprue is greater than in normal subjects. A similar observation was also made by Adibi et al. (1974) in three patients with coeliac disease. These observations underline the fact that either there are different transport systems for the dipeptide and amino acid or, if the same transport system is involved, the system must be more active for glycyl-glycine than for glycine absorption, so that when the transport system is progressively damaged it shows up first in the transport of glycine.

\section{APPEARANCE OF AMINO ACIDS IN LUMEN} DURING PERFUSION

In this study there was no significant difference 
between the two groups in the amount of glycine appearing in the aspirate when glycyl-glycine was perfused, but when glycyl-L-leucine was perfused, both free glycine and leucine accumulated within the lumen in tropical sprue patients at approximately twice the rate seen in control subjects. These two dipeptides are handled differently by the normal mucosa. Glycyl-glycine is absorbed almost entirely as the intact dipeptide and is readily detectable within the tissue (Matthews et al., 1969; Peters and MacMahon, 1970). On the other hand, glycyl-Lleucine is rapidly hydrolysed, probably mainly at the brush border (Fern et al., 1969) but also intracellularly; the specific activity of glycyl-L-leucine hydrolase is very high in the mucosa and intact dipeptide cannot be detected within the tissue in normal circumstances.

In the study of Silk et al. (1974) a similar increase in free amino acids in the perfusate was noted when glycyl-L-alanine was perfused in subjects with partial villous atrophy due to dermatitis herpetiformis. This dipeptide like glycyl-L-leucine undergoes more rapid hydrolysis than glycyl-glycine.

The increased accumulation of amino acids in the perfusate could result from intraluminal hydrolysis, but there is evidence that this does not occur to any significant extent (Matthews et al., 1969; Adibi, 1971). It is theoretically possible that increased hydrolysis occurred at the surface of the brush border in the patients with sprue, but this seems improbable, since in patients with sprue the brush border often shows morphological damage (Mathan et al., 1975) and other brush border enzymes are decreased (Swaminathan et al., 1970). A more likely explanation, in the presence of quantitatively normal enzymes, is that, once the dipeptide is in the cell, it is hydrolysed and 'back diffusion' of amino acids out of the cell is increased. This could result either from increased permeability of the luminal surface of the cell to the amino acids, or impairment of onward movement of amino acids across the serosal pole of the cell leading to a build up in their intracellular concentration with consequent increased 'back diffusion'. In support of this latter suggestion are the electron microscopic studies in tropical sprue showing thickening of the basement membrane region and accumulation of fat at this site, suggesting impairment to onward movement of lipid (Mathan et al., 1975).

\section{ENZYME CONCENTRATIONS}

There was no correlation between the concentrations of glycyl-glycine hydrolase or glycyl-L-leucine hydrolase and dipeptide absorption rates. There were also no significant differences between enzyme concentrations in the patients with sprue and those in control subjects. This contrasts with disaccharidase levels where a significant reduction is seen in tropical sprue (Swaminathan et al., 1970). Howevery, it should be emphasised that the enzyme measurements employed in this study were of 'total' enzyme content, $90 \%$ or more of which is intracellular dypeptidase. It has not yet been possible separately to measure pure brush border dipeptidases as distinct from those occurring in the cytosol in biopsy specimens. If the dipeptidases are concerned with dipeptide transport, it will presumably be those in the brush border which are more likely to correlate with peptide uptake. Furthermore, the already known reduction of disaccharidases in sprue suggests that the brush border dipeptidases might be affected even though the total dipeptidases as measured in this study are normal.

M.D.H. was in receipt of a research grant from the Endowment Fund, St. Thomas' Hospital, London. We wish to thank Dr Anne Gammon, Mr R. Jacob, Miss K. M. Roshini, and Miss N. Indirani for technical help.

\section{References}

Adibi, S. A. (1971). Intestinal transport of dipeptides in man: relative importance of hydrolysis and intact absorption. Journal of Clinical Investigation, 50, 2266-2275.

Adibi, S. A., Fogel, M. R., and Radheshyam, M. A. (1974). Comparison of free amino acid and dipeptide absorption in the jejunum of sprue patients. Gastroenterology, 67, 586-591.

Atfield, G. N., and Morris, C. J. O. R. (1961). Analytical separations of high-voltage paper electrophoresis. Amino acids in protein hydrolysates. Biochemical Journal, 81, 606-614.

Baker, S. J., and Mathan, V. I. (1972). Tropical enteropathy and tropical sprue. American Journal of Clinical Nutrition, 25, 1047-1055.

Butterworth, C. E., Santini, R., and Perez-Santiago, E. (1958). The absorption of glycine and its conversion to serine in patients with sprue. Journal of Clinical Investigation, 37, 20-27.

Crosby, W. H., and Kugler, H. W. (1957). Intraluminal biopsy of the small intestine. American Journal of Digestive Diseases, 2, 236-241.

Das, M., and Radhakrishnan, A. N. (1973). Glycyl-L-leucine hydrolase, a versatile 'master' dipeptidase from monkey small intestine. Biochemical Journal, 135, 609-615.

Fern, E. B., Hider, R. C., and London, D. R. (1969). The sites of hydrolysis of dipeptides containing leucine and glycine by rat jejunum in vitro. Biochemical Journal, 114, 855-861.

Hellier, M. D., Perrett, D., and Holdsworth, C. D. (1970). Dipeptide absorption in cystinuria. British Medical Journal, 4, 782-783.

Hellier, M. D., Radhakrishnan, A. N., Ganepathy, V., Gammon, A., and Baker, S. J. (1976). Intestinal absorption in normal Indian and English people. British Medical Journal, 1, 186-188.

Hyden, S. (1955). A turbidimetric method for the determination of higher polyethylene glycols in biological materials. Annales Agriculturae Fenniae, 22, 139-145. 
Josefsson, L., and Lindberg, T. (1965). Intestinal dipeptidases I. Spectrophotometric determination and characterization of dipeptidase activity in pig intestinal mucosa. Biochemica et Biophysica Acta, 105, 149-161.

Joske, R. A., and Haagensen, L. J. (1964). The 5 g. $d$-xylose absorption test. Journal of Clinical Pathology, 17, 154-155.

Klipstein, F. A., and Baker, S. J. (1970). Regarding the definition of tropical sprue. Gastroenterology, 58, 717-721.

Van de Kamer, J. H., Huinink, H., Ten Bokkal, and Weyers, H. A. (1949). Rapid method for the determination of fat in feces. Journal of Biological Chemistry, 177, 347-355.

Mathan, M., Mathan, V. I., and Baker, S. J. (1975). An electron-microscopic study of jejunal mucosal morphology in control subjects and in patients with tropical sprue in Southern India. Gastroenterology, 68, 1, 17-32.

Mathan, V. I., Swarnabai, S., and Baker, S. J. (1973). Intestinal absorption of radioactive vitamin $\mathbf{B}_{12}$ : a comparison of plasma, faecal and urinary tests. Indian Journal of Medical Research, 61, 714-723.

Matthews, D. M., Craft, I. L., Geddes, D. M., Wise, I. J., and Hyde, C. W. (1968). Absorption of glycine and glycine peptides from small intestine of rat. Clinical Science, 35, 415-424.
Matthews, D. M., Lis, M. T., Cheng, B., and Crampton, R. F. (1969). Intestinal absorption of some oligopeptides of Methionine and glycine in the rat. Clinical Science, 37, 751-764.

Peters, T. J., and MacMahon, M. T. (1970). The absorption of glycine and glycine oligopeptides by the rat. Clinical Science, 39, 811-821.

Rinaldo, J. A. Jr, and Gluckmann, R. F. (1964). Maximal absorption capacity of xylose in nontropical sprue. Gastroenterology, 47, 248-250.

Roe, J. H., and Rice, E. W. (1948). A photometric method for the determination of free pentoses in animal tissues. Journal of Biological Chemistry, 173, 507-512.

Silk, D. B. A., Kumar, P. J., Perrett, D., Clark, M. L., and Dawson, A. M. (1974). Amino acid and peptide absorption in patients with coeliac disease and dermatitis herpetiformis. Gut, 1, 1-8.

Swaminathan, N., Mathan, V. I., Baker, S. J., and Radhakrishnan, A. N. (1970). Disaccharidase levels in jejunal biopsy specimens from American and South Indian control subjects and patients with tropical sprue. Clinica Chimica Acta, 30, 707-712. 


\section{Notes and activities}

\section{Oxford Course in Postgraduate Gastro- enterology}

For the fifth year running, there will be a three day course on postgraduate gastroenterology in Oxford, 9-12 January 1977, for consultants and registrars, including those not specialising in gastroenterology. On this occasion, there will be four main topics: drugs and the liver, surgical problems with the bile duct, bile reflux and its consequences, and cancer of the large bowel. In addition, there will be a group of lectures on miscellaneous topics, such as viral gastroenteritis, Yersinia infections and the carcinoid syndrome. Anyone interested should apply to Dr S. C. Truelove, Nuffield Department of Clinical Medicine, Radcliffe Infirmary, Oxford.

American Association for the Study of Liver Diseases

A postgraduate symposium on viral hepatitis will be held on 3 and 4 November 1976, at Hyatt Regency Chicago, Chicago, Illinois, USA. Details may be obtained from AASLD Symposium, c/o Charles B. Slack, Inc. 6900 Grove Road, Thorofare, N.J. 08086, USA.

\section{Notes on books}

The Principles and Practice of Diagnostic Enzymology by J. Henry Wilkinson. (Pp. 592; illustrated; $£ 17 \cdot 50$ ) Edward Arnold: London. 1976. The extensive use of enzyme activity estimations as aids to the diagnosing of disease is one of the most impressive developments in modern medicine. This book will be the major source for reference in this field and will be needed in every hospital library. The liver, hepatobiliary tract, and alimentary tract are covered in depth, and the book will be consulted by gastroenterologists as well as by clinical biochemists.
Actinomycosis by Marcell Bronner and Max Bronner. (Pp. 355; illustrated; £8.00). John Wright: Bristol. 1971. This extensive survey of actinomycosis is primarily concerned with oral manifestations but the wealth of background information both in man and the animal world makes it a book worth having in general hospital libraries as a constant reminder to include this diagnostic possibility in abdominal problem cases.

Modern Stoma Care. Edited by Frank C. Walker. (Pp. 193; illustrated; price $£ 8 \cdot 00$ ). Churchill Livingstone, Edinburgh. 1976. This book provides a comprehensive account of the management of the three main abdominal stomata. It gives details of the support provided by the community health services, together with specialised advice on the problems of skin care, the choice of appliance, the organisation of stoma clinics, and requirements of stoma therapists. Each section has been compiled by experts in the field and is based on personal experience and research. The information it contains will be of use to the doctor, nurse, and stoma therapist, as well as patients obliged to live with a permanent stoma.

Taking the Rough with the Smooth. Dietary Fibre and Your Health-a New Medical Breakthrough by .Andrew Stanway. (Pp. 255; £3.50). Souvenir Press: London. 1976. This book is of equal interest to the general public and to the profession. The evidence for taking less sugar and more unrefined cereal in the diet has become impressively strong. A paperback edition will be forthcoming and this will enable it to reach a wider audience. In the meantime, all concerned with instructing students and paramedical staff should have a copy available.

\section{Correction}

'Intestinal perfusion studies in tropical sprue' by M. D. Hellier et al. (Gut, 1976, 17, 511-516).

The authors regret that the headings in Fig. 4 were transposed.

Authors who wish to have their manuscripts acknowledged are asked to enclose a stamped addressed postcard or an international reply coupon. 